\title{
Desenhos Narrativos: Workshop do Laboratório Transdisciplinar de Ceno- grafia (LTC) na Quadrienal de Praga 2019
}

\author{
Sônia Maria Caldeira Paiva \\ Universidade de Brasília - UnB, Brasília/DF, Brasil \\ E-mail: soniamcpaiva@gmail.com \\ Caio Sato Schwantes \\ Universidade de Brasília - UnB, Brasília/DF, Brasil \\ E-mail: caio.schwantes@gmail.com \\ Luana Santana Castro \\ Universidade de Brasília - UnB, Brasília/DF, Brasil \\ E-mail: luascastro@hotmail.com \\ Matheus MacGinity Moraes Rêgo \\ Universidade de Brasília - UnB, Brasília/DF, Brasil \\ E-mail: matheus.macginity@gmail.com
}

Carolina Guida Teixeira

Universidade de Brasília - UnB, Brasília/DF, Brasil

E-mail: carolinaguidateixeira@gmail.com

Carlos Eduardo Peukert

Universidade de Brasília - UnB, Brasília/DF, Brasil

E-mail: cacocontato@gmail.com

Bruna Camurça Freitas

Universidade de Brasília - UnB, Brasília/DF, Brasil

E-mail: bruna_camurca@hotmail.com

$$
\text { Julia Horta Paiva }
$$

Universidade de Brasília - UnB, Brasília/DF, Brasil

E-mail: juhortapaiva@gmail.com

Sarah Brochado Fialho

Universidade de Brasília - UnB, Brasília/DF, Brasil

E-mail: sarahbfialho@gmail.com 
O presente ensaio explora, por meio de uma escrita criativa e colaborativa em formato de Tramóia, o projeto Desenhos Narrativos realizado pelo Laboratório Transdisciplinar de Cenografia (LTC) - Programa de Extensão de Ação Contínua (PEAC) da Universidade de Brasília (UnB), criado e coordenado pela Profa. Dra. Sônia Paiva - para Quadrienal de Praga (PQ) de 2019. O workshop, apresentado na programação da PQStudio, compõe parte do repertorio do laboratório que opera, desde de 2010 , visando atingir uma de suas principais metas: entregar para o público experiências multiculturais e transdisciplinares, vindas das ações constantes que interconectam as pesquisas e práticas do laboratório. Ao longo dos diálogos da Tramóia são abordados temas relacionados ao projeto: dinâmicas de criação e produção do LTC, relação e percepção do públi$\mathrm{co}$, conceitos e metáforas do grupo, dentre outras.

\section{Palavras-chave}

Trama. Desenho. Colaboração.

Transdisciplinaridade. Etnomatemática.
This essay explores, through creative and collaborative writing in a Tramóia format, the Narrative Drawings project conducted by the Transdisciplinary Scenography Laboratory (LTC) - Continuous Action Extension Program of the University of Brasília (UnB), created and coordinated by Profa. Dr. Sônia Paiva - for Prague Quadrennial (PQ) 2019. The workshop, featured in PQStudio's programming, is part of the laboratory repertoire which has been operating since 2010 to achieve one of its main goals: delivering multicultural and transdisciplinary experiences to the public as a result of constant deeds that interconnect research and actions of the laboratory. Throughout the dialogues of the Tramóia, themes related to the project are addressed: LTC creation and production dynamics, relation and perception of the spectator, group concepts and metaphors, among others.

\section{Keywords}

Weft. Design. Collaboration. Transdisciplinarity. Ethnomathematics. 


\section{Uma reunião imaginária}

Este ensaio foi construído a partir dos encontros regulares do Laboratório Transdisciplinar de Cenografia (LTC) - um Programa de Extensão de Ação Contínua (PEAC) da Universidade de Brasília (UnB), criado e coordenado pela profa. Dra. Sônia Paiva. Trata-se de uma escrita criativa e colaborativa do grupo, sobre como o LTC opera, desde 2010, para atingir uma de suas principais metas: entregar para o público experiências multiculturais e transdisciplinares, vindas das ações constantes que interconectam as pesquisas, metodologias e práticas do laboratório.

O último projeto realizado pelo LTC que alcançou esse objetivo foi o workshop The Drawing Narratives Experience ${ }^{1}$, apresentado na Theatre Faculty of Academy of Performing Arts in Prague $(D A M U)^{2}$, como parte da programação da $P Q-$ Studio $^{3}$, na Quadrienal de Praga (PQ) de 2019. Ao longo deste texto, o grupo engendra uma reunião imaginária, tendo como base diálogos estruturados a partir de temas propostos por nossa moderadora, Patrícia Meschick - integrante do LTC há dez anos, que não participou diretamente da construção do workshop.

\section{A Tramóia}

Cada tema é um nó a partir do qual se tece uma rede de interações, ou melhor, uma tramóia. É uma tecedura entre: os fundamentos apresentados pela professora Sônia Paiva em seu doutorado4; as práticas, experiências, metodologias e projetos desenvolvidos coletivamente e as reverberações

\footnotetext{
1 Tradução título original: ‘Desenhos Narrativos'.

2 Faculdade de Teatro da Academia de Artes Performáticas de Praga. Mais informações: <https://www.damu.cz/en/>.

3 Programação de workshops, masterclasses e diálogos internacionais, criada pela PQ19, sob a curadoria de Patrick Du Wors. Mais informações: <https://www.pq.cz/2018/03/27/pq-studio-3/>.

4 O Laboratório Transdisciplinar de Cenografia (LTC): locus do espaço e desenho da cena no Brasil. Disponível em: http://repositorio.unb.br/handle/10482/20602.
}

das percepções individuais dos membros. Tecemos assim, juntos, uma cultura holística que oferece ao outro a Etnomatemática ${ }^{5}$ do laboratório.

Figura 1 - Tramóia: renda de bilro produzida em Florianópolis, Santa Catarina.

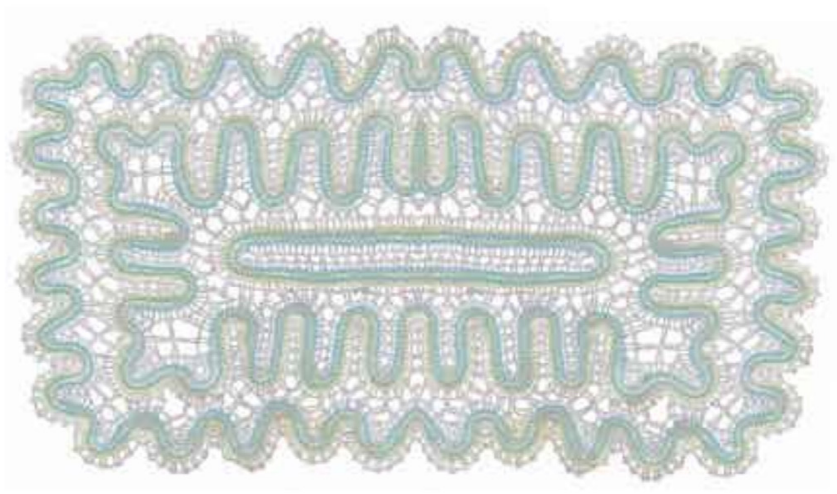

Fonte: Acervo do grupo.

A Tramóia ${ }^{6}$, também conhecida como renda de sete pares, é uma prática oriunda da Bélgica, incorporada à cultura brasileira a partir da influência açoriana no século XVIII. Este tecido, constituído por interligações de nós, nos serve como imagem para o entendimento das ações e relações interconectadas que fazemos e que nos refletem como um desenho coletivo. Desse modo, apresentaremos a seguir um diálogo de forma que uma rede é desenhada pelas conexões entre conhecimentos e insights dos integrantes do LTC sobre o percurso de criação, produção e execução do workshop Desenhos Narrativos em Praga.

[Na Tramóia] a forma linear já não existe, não trabalhamos

\footnotetext{
5 Pesquisa desenvolvida pelo matemático e professor emérito da Universidade de São Paulo (USP) Ubiratan D'Ambrósio, motivado pela procura de entender o saber/fazer matemático ao longo da história da humanidade, contextualizado em diferentes grupos de interesse, comunidades, povos e nações (D'AMBRÓSIO, 2001). A etnomatemática não se limita à Matemática, ela é transdisciplinar: parte da realidade e chega, de maneira natural, à ação pedagógica, através de um enfoque cognitivo com forte fundamentação cultural. Mais informações em: http://ubiratandambrosio.blogspot.com/.
}

6 Este experimento iniciou-se a partir da constatação, em 2013, de um dos antigos membros do LTC, Flávio Café, de que o ensino praticado no laboratório é tecido tal qual uma renda de bilro. 
para um resultado específico e, sim, para a construção da própria rede, na qual tudo é modulado, relaciona-se indisciplinarmente; e em que os participantes navegam e determinam seus caminhos de ligações entre as ações. (PAIVA e VERAS, 2014, p.49).

Sendo assim, o texto é construído como uma conversa ao redor de uma mesa de trabalho no Parque de Produções ${ }^{7}$. Nessa conversa, após retornar de viagem, o grupo do LTC está fazendo um balanço da sua participação em um cenário internacional e multicultural como a PQ19. Abordam, assim, o conhecimento produzido e adquirido ao longo da construção do workshop Desenhos Narrativos e suas percepções sobre seu resultado.

Figura 2 - LTC e participantes da última apresentação do workshop Desenhos Narrativos na PQ19.

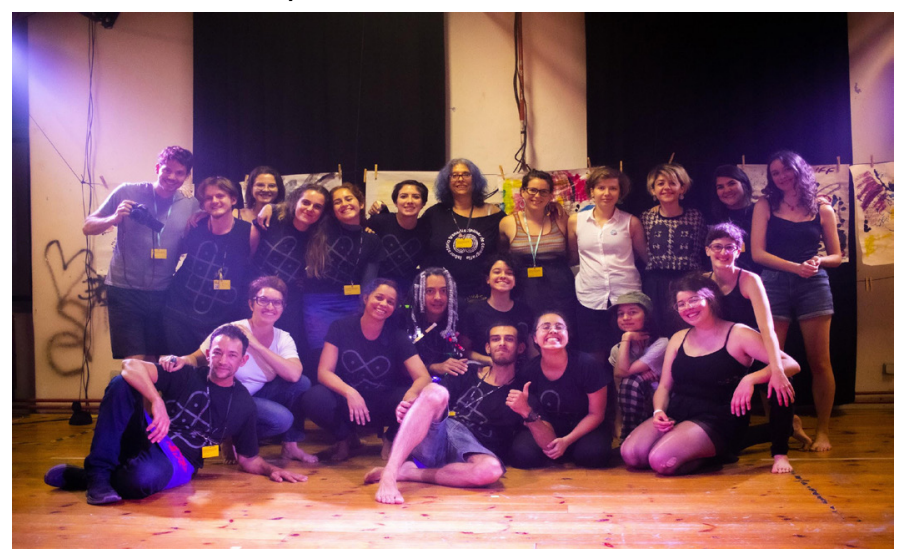

Fonte: Acervo do grupo.

Tomamos como base para essa escrita os materiais produzidos pelo grupo, tal como o storyboard - importando do cinema, um dos principais documento de direção, criação e gestão do projeto. Outras ferramentas implementadas por Sônia Paiva na cultura de trabalho do LTC são: mapas mentais, cadernos de processo, registros em foto e vídeo, registros que fomentam nosso repertório mnemônico.

7 Espaço colaborativo, de Sônia Paiva localizado na Serrinha do Paranoá (Brasília-DF), de criação e produção, com múltiplos ateliês. Mais informações: http://www.parquedeproducoes.com/.
Tivemos como objetivo alcançar as diversas visões da rede de trabalho que formamos, entre ações, reações e reverberações do fazer e do significar, como um percurso de comunicação labiríntica.

\section{Os fios que tecem a Tramóia}

A fim de dar início à rede da Tramóia e contextualizar os diálogos e as atuações do LTC é preciso dispor primeiramente os fios que compõem nossos fundamentos: a etnomatemática, a transdisciplinaridade, a colaboração, o multiculturalismo, as múltiplas inteligências e a economia criativa; e os fios de nossas ações: criação, gestão e formação de projetos culturais e educacionais.

O Laboratório Transdisciplinar de Cenografia $($ LTC) 8 foi criado em 2010, com a formação de grupos compostos por alunos universitários de diferentes áreas, para a participação na Mostra das Escolas Brasileiras da Quadrienal de Praga de 2011 (PQ11). Nesse processo do laboratório, foram firmados dois dos principais fundamentos: a transdisciplinaridade e a colaboração, uma vez que entendemos que o conhecimento se dá na ética da cooperação, respeito e solidariedade. Transdisciplinaridade é, antes, saber que não há hierarquia na forma de adquirir um conhecimento. Também não é uma mistura de todas as ciências do mundo, mas sim uma ampliação nas formas de encontrar respostas (D’AMBRÓSIO, 2012).

Na edição da Quadrienal em 20159 Sônia Paiva foi curadora da Mostra dos Estudantes Brasileiros e desenvolveu com o LTC o projeto Brasil: LABirintos Compartilhados ${ }^{10}$ (PAIVA, 2015), que abria portas para a participação da diversidade brasileira das escolas de várias regiões do país, em Praga. $\mathrm{O}$

8 Histórico retirado do artigo de Sônia Paiva - O Laboratório Transdisciplinar de Cenografia (LTC) e a x. Quadrienal de Praga. Disponível em: https://www.academia.edu/33683505/O_Laborat\%C3\%B3rio_Transdisciplinar_de_Cenografia_LTC_e_a_ Quadrienal_de_Praga.docx.

9 Projetos do Brasil na PQ15: https://pqbrasil.org/2015.

10 Mais informações: https://brasillabirintoscompartilhados.wordpress.com/. 
projeto trabalhou para a ampliação da representação territorial do Desenho da Cena no Brasil111, uma vez que entendemos o Desenho da Cena como um espaço aberto a ser modificado pelas relações entre múltiplas culturas e disciplinas. Isso constrói uma ecologia de saberes transdisciplinares do LTC que, por meio das artes, ciências, tecnologia, educação, ecologia, comunicação e ciências humanas, promove um campo fértil para criação de projetos sustentáveis, que unam o resgate do fazer artesanal aos recursos da atualidade e suas discussões.

Figura 3 - Brasil: LABirintos Compartilhados, a Mostra dos Estudantes Brasileiros na PQ15.

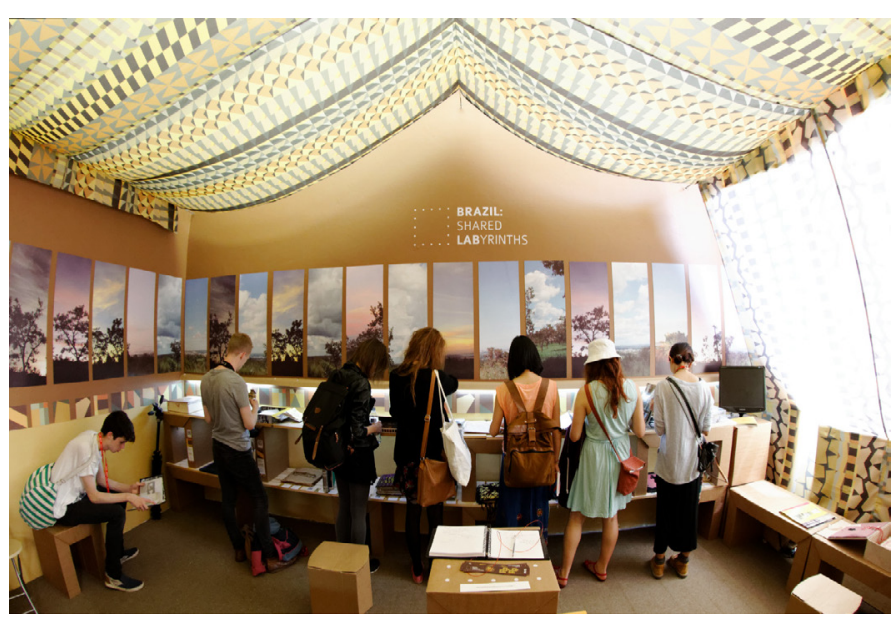

Fonte: Acervo do grupo.

Em 2016, o LTC deu início ao projeto Desenhos Narrativos, com sua primeira apresentação no Departamento de Artes Cênicas da Universidade de Brasília (UnB), assumindo uma estrutura intimista, de teatro de câmara, em que todo o público atuava no espetáculo. Essa primeira experiência antecedeu a apresentação do espetáculo na Funarte, intitulado "Desenhos Narrativos: da Areia a Luz", na programação "Terra e Luz: Poéticas da Matérias, uma colaboração Brasil - França", produzido pelo LTC em colaboração com Coletivo Terrón ${ }^{12}$ e Lado

11 Ao total, 20 escolas enviaram 64 projetos, dos quais foram selecionados 33 para a exposição na Quadrienal.

12 Grupo de experimentação e criações interdisciplinares em torno da questão da Terra, a fim de levá-la para a cena. Com sede em Grenoble (França).
Brasil $^{13}$. Essa apresentação, em um teatro de semi-arena com capacidade para mais de 300 pessoas, nos mostrou a necessidade de avaliar estratégias para convidar o público a desenhar e integrar o espaço da cena, uma vez que nessa nova dimensão espacial, perdemos a intimidade e a interação alcançada na primeira apresentação do projeto.

Em janeiro de 2018, retornamos ao projeto Desenhos Narrativos com uma imersão realizada em Goiás Velho ${ }^{14}(\mathrm{GO})$, onde redefinimos a estrutura do espetáculo para o espaço do Teatro Sesc Garagem (Brasília). A partir desse trabalho, no qual desenvolvemos novas soluções para convidar efetivamente o público a participar de nosso desenho colaborativo da cena, encontramos no termo 'actantes' ${ }^{15}$ a forma mais adequada de nomear esse público que é agente do ato de criar.

Figura 4 - Teste de maquiagem para o Xamã, do espetáculo Desenhos Narrativos: da Areia à Luz.

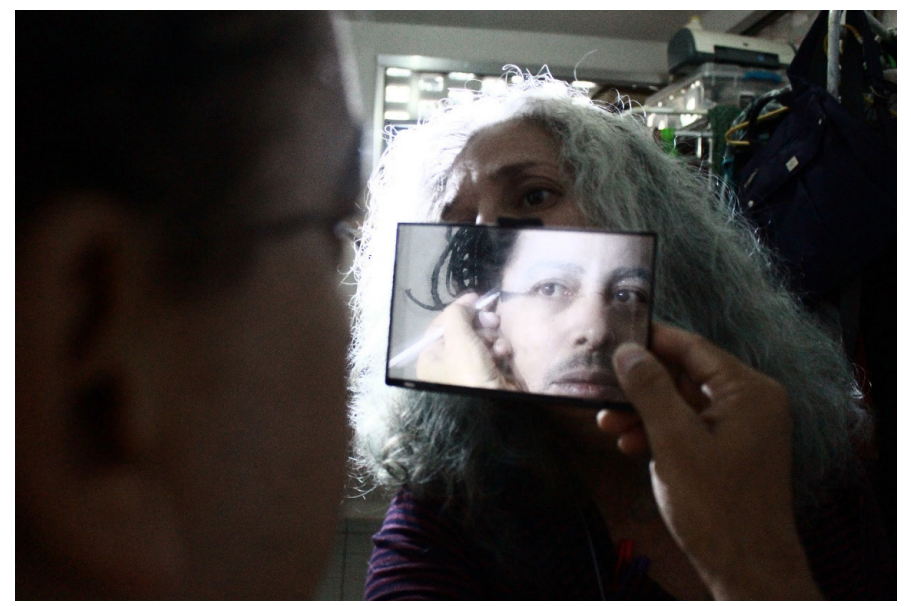

Fonte: Acervo do grupo.

No Teatro Sesc Garagem também produzimos a Loja Volante do LTC, com produtos referentes a identidade visual do Desenhos Narrativos e

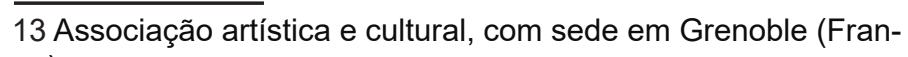
ça).

14 As imersões do LTC na Cidade de Goiás são realizadas na casa da família de Sônia Paiva. A casa é patrimônio histórico da cidade.

15 Termos frequentemente utilizado em estudos de Semiótica e Linguística, indica o agente atua em uma ação. 
de design exclusivo do laboratório. A Loja é parte das ações de economia criativa ${ }^{16}$ desempenhadas pelo grupo, assim como a realização de campanhas de financiamento coletivo e eventos culturais. Por exemplo, produzimos o evento "Grito Cultural" em maio de 2019 no Parque de Produções que foi uma resposta a ausência de editais de fomento a cultura, além de uma forma de difundir nosso trabalho. Contando com uma programação de oficinas, galeria e sarau, o Grito visava a captação de recursos financeiros para a ida do Desenhos Narrativos à $P Q$.

Em junho de 2019, apresentamos na PQ19 o workshop Desenhos Narrativos, aperfeiçoando a estrutura do espetáculo a um workshop. Para tal, construímos uma atmosfera imersiva, performática e formativa pensando sempre no espaço no qual ele ocorreria: a sala de aula da DAMU.

A edição da Quadrienal de 2019 foi estruturada a partir de três eixos temáticos como guias: imaginação, transformação e memória. Os eixos estruturam a programação, com diversas chamadas públicas internacionais, sendo uma delas a PQStudio, da qual nosso workshop foi selecionado para fazer parte da programação. Com quatro sessões de quatro horas de duração cada, estruturadas para 12 participantes e divididas ao longo de dois dias, o workshop é constituído de quatro partes ${ }^{17}$.

A primeira é a apresentação de um elemento teatral do espetáculo: a figura mítica do Xamã, que fala da origem das várias Etnomatemáticas do mundo. A segunda é um convite a experimentar a Etnomatemática com os desenhos sona de Angola imagens topográficas que o povo cokwe desenhava na areia para transmitir sua cultura, seus conhecimentos, lendas e leis entre as gerações. O ponto

16 A Economia Criativa entende que os ciclos de criação, produção e distribuição de bens e serviços criativos, culturais e intelectuais geram valor humano, diversidade cultural e possibilidade de crescimento econômico.

17 Estudos de Etnomatemática, a teoria "Ponto, Linha e Plano" de Kandinsky e a técnica de Light painting são abordadas em pesquisas e experimentos desenvolvidos na tese de doutorado de Sônia Paiva e são refletidos nos processos de criação do LTC. de partida é o sistema de coordenada, um grid, que estrutura os desenhos feitos de forma contínua pelo desenhador enquanto narra. A terceira parte é inspirada pela teoria do artista Kandinsky "Ponto, Linha e Plano", que apresenta o ponto como o elemento original da pintura e a linha como o rastro do ponto no espaço. Assim, conduzimos os participantes a explorar a sinestesia entre sons, cores e gestos. Este momento é a ponte entre a segunda e a quarta parte do workshop, e edifica o fio narrativo do mesmo. O Light painting - pintura com luz - é a quarta e última etapa e consiste na técnica de longa exposição fotográfica, que captura os rastros de luz a partir do corpo em movimento. As imagens são projetadas no espaço, desenhando a cena a partir da ação dos participantes.

É sempre na relação entre o
fazer e o pensar que se en-
contra nossa proposta artística/
educacional, as duas forças,
juntas e conectadas, intercala-
das ou sobrepostas por meio
de ações, multidirecionadas,
em processos vários e diver-
sos, formam um mapa, uma
rede que conecta um processo
conjunto, diverso e compar-
tilhado. (PAIVA, 2016, p.44).

Nossos processos criativos são causa e consequência da construção da nossa própria Etnomatemática que criamos enquanto coletivo LTC. Temos Etno - nosso ambiente social, cultural e imaginário; Matema - a forma como conhecemos e lidamos com os problemas; e Tica - modos, técnicas, estilos e arte que adotamos para desenvolver estes conhecimentos.

\section{Tramóias de um workshop}

Após a volta de Praga, alguns membros do Laboratório Transdisciplinar de Cenografia se reúnem no Parque de Produções para discutir sobre o trabalho e tudo que foi vivenciado. Estão presentes à mesa Sônia Paiva, Bruna Camurça, Caco Tomazzoli, Caio Sato, Carolina Guida, Júlia Horta, Lua 
Castro, Matheus MacGinity, Sarah Fialho e Patrícia Meschick. Há pão de queijo assando no forno e algumas pessoas trouxeram petiscos, em cima da mesa se encontram os diversos storyboards, cadernos do processo, anotações, materiais gráficos, HD's externos... Todo o registro mnemônico do grupo.

Patrícia inicia a reunião, questionando como o grupo sentiu a experiência de apresentar o workshop em um espaço internacional: - E aí, gente!? Como foi o trabalho do LTC lá em Praga? BRUNA: - Patrícia, foi incrível! Eu não esperava tamanha diversidade! Foram pessoas de países e culturas muito diferentes. Recebemos actantes do Canadá, Makao, da própria República Tcheca... Austrália, Finlândia, Taiwan, EUA, Grécia... Também tinha... Grã Bretanha, Brasil, Colômbia, Costa Rica, Bulgária... Macedônia... Acho que esses... LUA: - A diversidade de países e das culturas também me surpreendeu. Foi aí que senti que o nosso workshop "ganhou corpo", já que construímos o Desenhos Narrativos justamente como um espaço para que pessoas diversas, com culturas diversas, se encontrassem, se apresentassem umas para as outras e criassem algo juntas! MACGINITY: - Concordo! Foi aí que eu entendi a Etnomatemática das diferentes culturas. Em uma das sessões, durante a prática sinestésica de pintura e som, reparei no modo como duas actantes de Taiwan reverberavam seus gestos no papel de forma delicada, com desenhos longos e sutis. Uma delas inclusive diluiu as tintas que tínhamos disponibilizado e transformou em aquarela. Eu ainda não tinha visto isso em outras edições do workshop. Em nossas experiências no Brasil, constantemente alguém acabava rasgando o papel pela força dos movimentos e excesso de tintas. Ficou claro naquele momento como temos modos diferentes de reverberar quem somos.
Figura 5 - Pintura realizada por uma actante de Taiwan durante o workshop na PQ19.

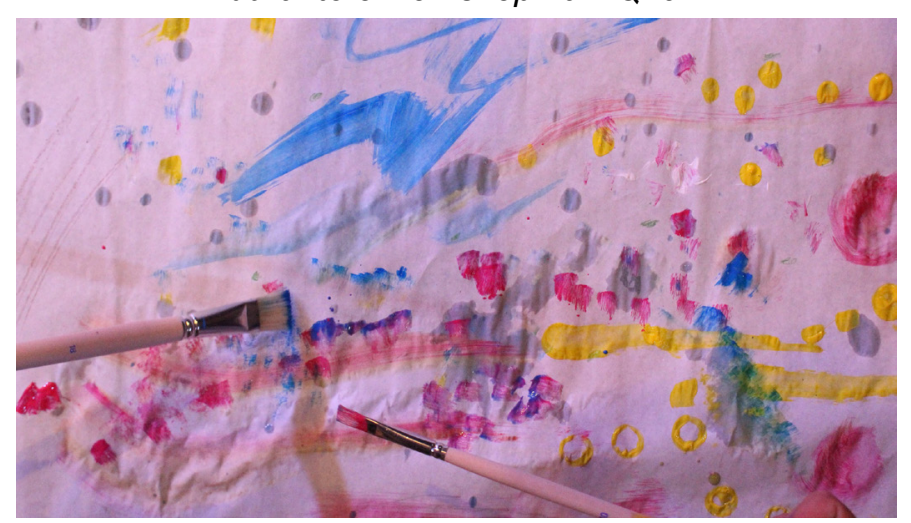

Fonte: Acervo do grupo.

LUA: - E podemos refletir sobre a Etnomatemática não somente de um país, mas de um grupo também. Ao longo do processo do 'Desenhos Narrativos', por exemplo, compartilhamos conhecimentos, técnicas e referências; termos foram criados ou ressignificados, fazendo sentido só para nós, e que formaram nossa linguagem. Essas coisas são parte da Etnomatemática desse projeto e, inclusive, me fazem pensar quanto do 'Desenhos Narrativos' e do LTC existe no meu modo de pensar, nas minhas decisões... Nossa, nas minhas decisões, com certeza! Eu nunca me imaginei indo para a Quadrienal de Praga, até porque eu nem saberia da existência do festival, e do universo de possibilidade que ele pode abrir, se não fosse o laboratório. Vivenciar a cultura, a Etnomatemática do LTC reconfigura todos os dias o meu modo de ser e agir no mundo. E então quando eu me expresso, reverbero um pouco do laboratório também, certo? Acho que é assim com todo mundo, né? SÔNIA: - Sim, porque a forma de trabalho e de convivência colaborativa que procuro propor com o LTC expande nossa visão multidimensional da vida. Isso se reflete nos projetos produzidos coletivamente dentro do laboratório, mas também nos trabalhos individuais de cada um de vocês. BRUNA: - E é essa a experiência que entregamos aos participantes no workshop: a expansão de suas visões sobre si, sobre o outro e o mundo. Queremos que eles saiam de lá conscientes de suas multiplicidades! 
Figura 6 - Actantes durante experiência de pintura e som.

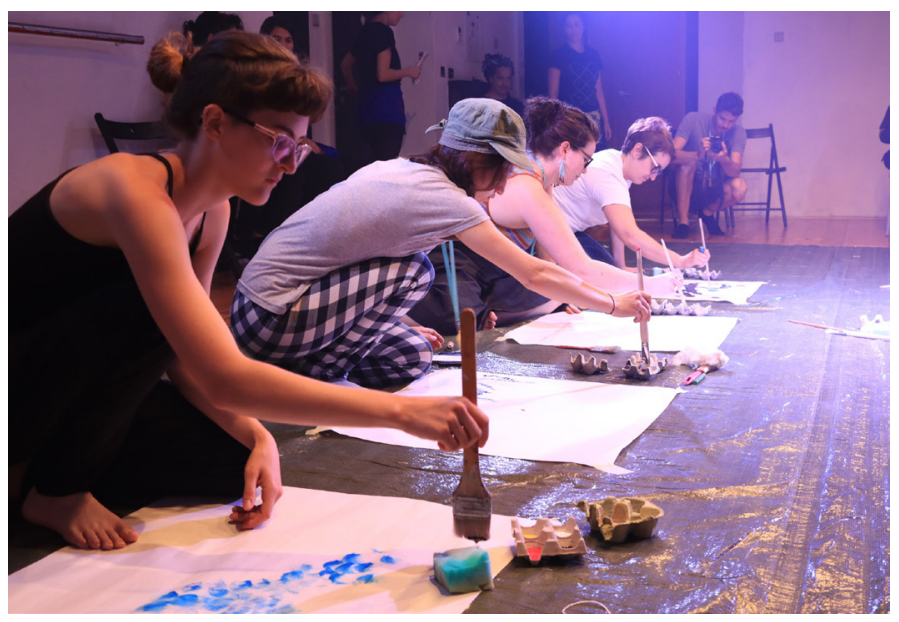

Fonte: Acervo do grupo.

LUA: - Bruna, quando você diz isso eu só consigo pensar no quanto é realmente genial a metáfora do restaurante que a Sônia nos apresentou, e o que desenvolvemos com ela. Quando assumimos esse lugar de 'entregar', 'servir' o outro, tudo mudou. Eu pelo menos mudei muito! Durante o processo de produção do workshop, assumo que tive muita dificuldade de me comunicar com o grupo e de estar realmente em colaboração. Quando a Sônia trouxe a metáfora, ela me trouxe para dentro do projeto como eu nunca estive antes, porque trata-se de uma linguagem que eu tenho muita familiaridade, pelos anos que trabalhei como atendente em bares. E eu que pensava que toda essa minha experiência não tinha nada a ver com teatro, me vi finalmente consciente de como eu poderia assumir a postura que o projeto demandava: de disponibilidade e prontidão ao outro. Estou aprendendo com isso até hoje, na verdade. SÔNIA: - Refleti muito sobre esse meu insight de comparar o nosso trabalho com o ato de cozinhar e servir. Foi um elemento chave que definiu o desenho da cena do workshop, no último momento. Uma metáfora que possibilitou clareza no papel de cada um, uma vez que tínhamos um grupo tão heterogêneo, no sentido de tempo de vivência no LTC, e de suas diversas linguagens e conhecimentos. Além de estabelecer melhor as funções de cada componente e determinar as circulações do grupo no espaço, definiu a relação do grupo com os participantes: servir experiências. Sendo assim, o espaço do workshop se estruturou como uma grande mesa, marcada pela lona que protegia o chão da sala para as práticas. Os elementos teatrais da iluminação, da projeção e do som ambientavam nosso restaurante e as equipes apresentavam e facilitavam as experiências para os nossos convidados: os actantes.

Figura 7 - O espaço do workshop se estruturou como

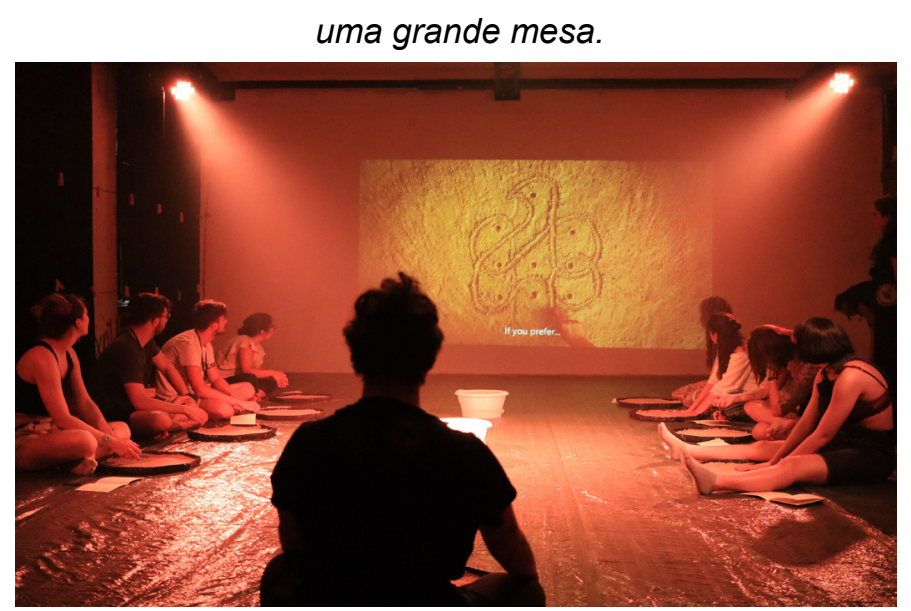

Fonte: Acervo do grupo.

PATRICIA: - A metáfora é mesmo ótima! Desenha bem workshop, eu consigo visualizá-lo facilmente. Mas, Sônia, de onde você tirou isso? SARAH: - Lembro que Sônia nos apresentou a metáfora do restaurante citando Van Gogh. Em uma das cartas que ele escreveu para seu irmão, Théo, Van Gogh fez uma comparação dizendo que pintar se assemelha ao ato de cozinhar. Porque o pintor, assim como o cozinheiro, precisa selecionar seus utensílios, preparar e porcionar os ingredientes antes de começar o trabalho. Na cozinha, esse processo se chama mise en place. É literalmente dispor, "pôr em ordem" em francês, não é isso? SÔNIA: - Exatamente! A partir daí, apresentamos as quatro partes do workshop como quatro pratos de um menu: a apresentação do Xamã é um amouse bouche, que é um aperitivo oferecido pelo Chef para abrir o paladar dos convidados; Etno- 
matemática, Kandinsky e Light painting são entrada, prato principal e sobremesa, respectivamente.

Figura 8 - Eric Costa como o Xamã no workshop Desenhos Narrativos na PQ19.

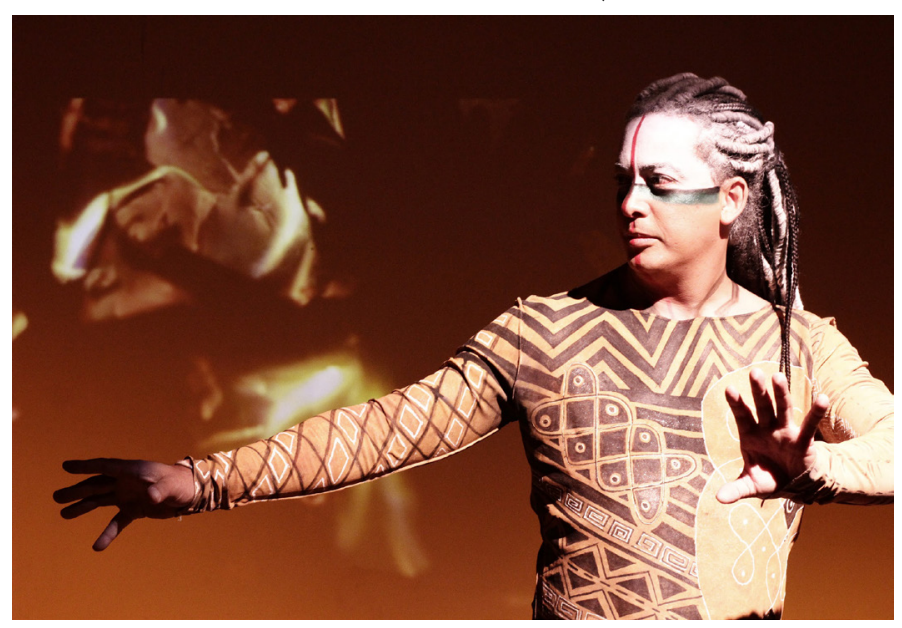

Fonte: Acervo do grupo.

SÔNIA: - Também organizamos nossas equipes de trabalho tal qual o operacional de um restaurante: temos os cozinheiros, que são nossos técnicos de luz, som e imagem, que desenhavam o ambiente do workshop; o back of the house, que é a equipe de backstage de um restaurante e administra a organização do espaço, dos materiais e a montagem da cada uma das etapas do workshop; e o front of the house do restaurante, equipe que se dispõe a serviço dos convidados e que, no workshop, apresenta e exemplifica as dinâmicas de cada etapa. Como diretora do projeto, me apresento como Chef, quem conduz a experiência dos actantes. SÔNIA: - Caco, quer falar sobre sua visão como assistente de direção? CACO: - Vejo que, quando a Sônia está atuando como Chef, ela está, na verdade, lançando mão de uma boa parte dos seus estudos e práticas, para que o desenho da cena seja uma experiência exitosa para os actantes. Como nossas cenas eram totalmente dinâmicas e iam se remodelando conforme a ação dos actantes, não me bastava, como sous chef, dar suporte operacional-técnico no planejamento da montagem, nas adaptações dos espaços e dos entreatos. Minha principal operação neste trabalho era a de manter minha ação em alto nível de conexão com a ação transdisciplinar da Sônia.

Figura 9 - Nossos cozinheiros da luz, projeção e som: Caco Tomazzoli, Caio Sato e Matheus MacGinity.

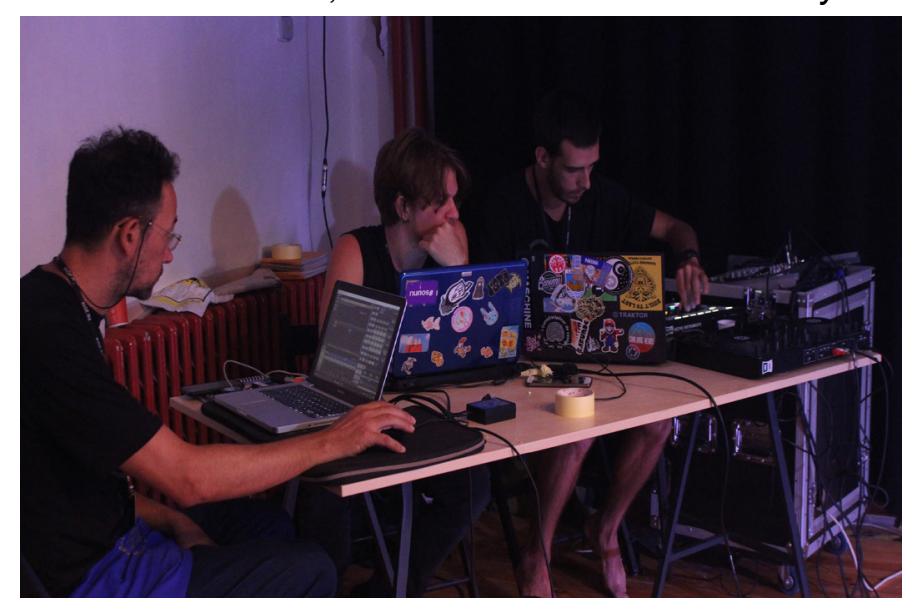

Fonte: Acervo do grupo.

Figura 10 - Front of the house ensinando os desenhos sona na areia aos actantes.

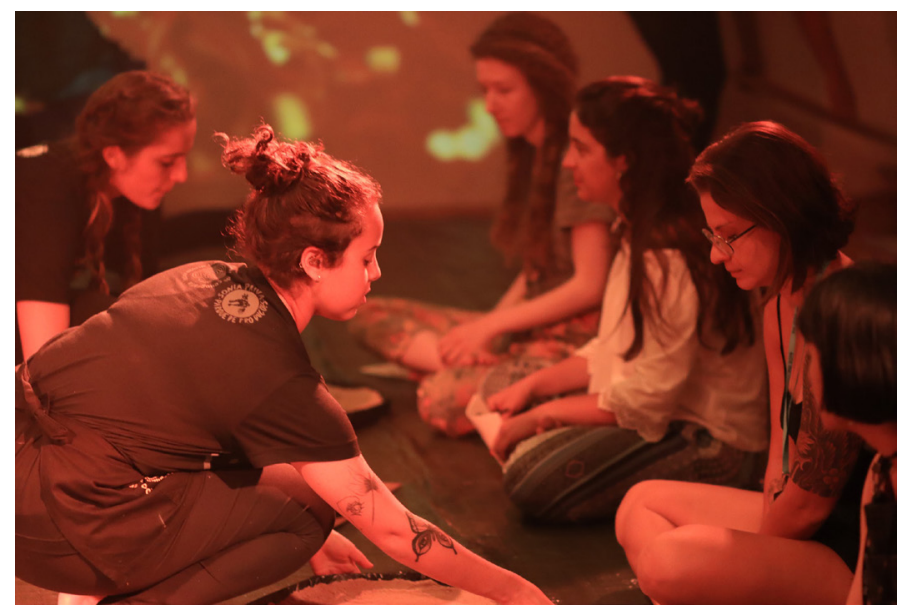

Fonte: Acervo do grupo.

LUA: - Era legal reparar na reação dos actantes quando a Sônia apresentava a metáfora. Várias pessoas riam, achavam divertido, e outras ficavam com cara de "como assim, galera?", meio desconfiadas... Porque de fato é surpreendente, é uma maneira meio inusitada de enxergar a situação. Mas aí a Sônia seguia, apresentando as equipes, os pratos do menu... E as pessoas iam se familiarizando com a 
metáfora, afinal ela vem de um imaginário comum a todas as culturas, todo mundo ali já havia frequentado algum tipo de restaurante, e isso já remetia a relação de degustar, experimentar... Conhecimentos, no nosso caso! Vejo que a metáfora foi importante para o nosso operacional como equipe, mas também foi uma peça chave na experiência dos participantes, porque o desenho da cena do workshop ficou muito acessível a eles também. Ajudou todo mundo a imergir no universo que construímos! CAIO: - O preparo do espaço visual feito pelos cozinheiros também foi fundamental para essa imersão. Misturamos as projeções de vídeo, temperadas com o panorama sonoro criado pelo MacGinity e levemente aquecidas ou resfriadas pela aclimatação luminosa desenhada pelo Caco... Um resultado bonito dessa mistura é o momento de entrada dos actantes no espaço: na parede, a imagem da queda d'água que MacGinity e eu gravamos em Goiás Velho, com uma cor bem mais azulada, que combinava com o leve toque de ciano que o Caco trazia na luz, e o som de água correndo ocupando a sala. Atuamos, assim, os três em consonância...

Figura 11 - Pesquisa de som durante imersão do LTC em Goiás Velho.

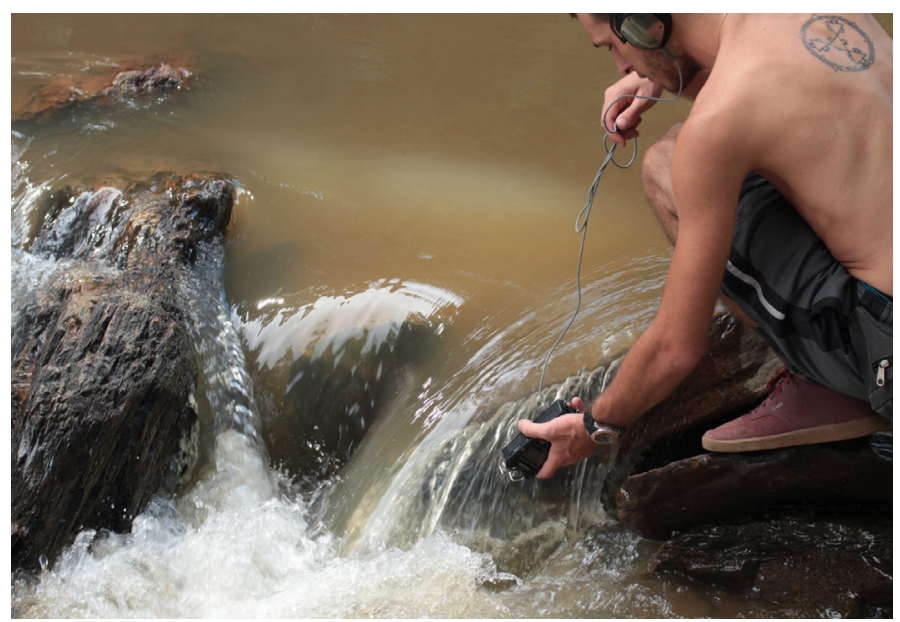

Fonte: Acervo do grupo.
Figura 12 - Resultado da projeção na parade da sala da DAMU no workshop na PQ19.

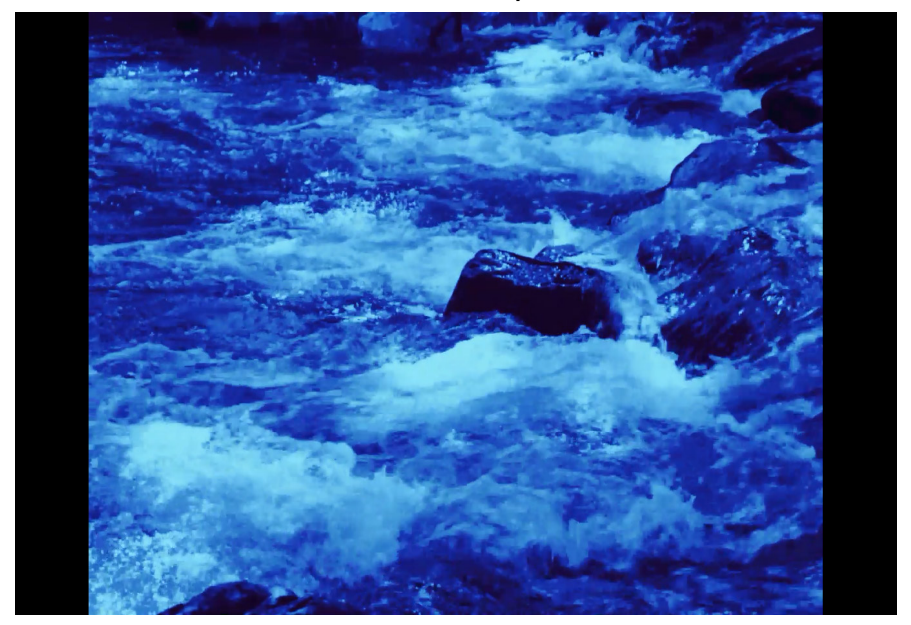

Fonte: Acervo do grupo.

CACO entra na sala de repente, com os pães de queijo que acabaram de sair do forno e café: - Mais do que isso, buscamos a consonância também com os actantes. Lembra de nossa preocupação em ficar olhando constantemente para a cena, ao invés de simplesmente seguir o storyboard? Tínhamos que fluir o storyboard programado, sem deixar de perceber e agir de acordo com os acontecimentos do momento. CAIO:-É verdade! Só assim, com essa atenção e cuidado, foi possível a criação de um ambiente imersivo onde todos permaneciam sintonizados durante toda a experiência: a atuação da técnica, a logística do back of the house, a ação da narradora, a interpretação do front of the house e a experimentação dos actantes. PATRICIA: - Entre os integrantes que entraram no LTC mais recentemente, o que vocês acharam dessa dinâmica de trabalho? GUIDA: - Foi interessante a sincronia e o timing da equipe, mesmo sem muitos ensaios... SÔNIA: - Mas, Guida, o trabalho de storyboard que elaboramos nos encontros do hotel em Praga, onde entendemos e desenvolvemos melhor a metáfora do restaurante, traçamos as logísticas e demandas de cada equipe, marcamos e revisamos diversas vezes o timing das ações e seus responsáveis... Não poderia, também, ser considerado como ensaio? [No meio de todos os papéis em cima da 
mesa, Sônia encontra o storyboard impresso].

Figura 13 - Página do storyboard desenvolvido pelo LTC para o Desenhos Narrativos em Praga.

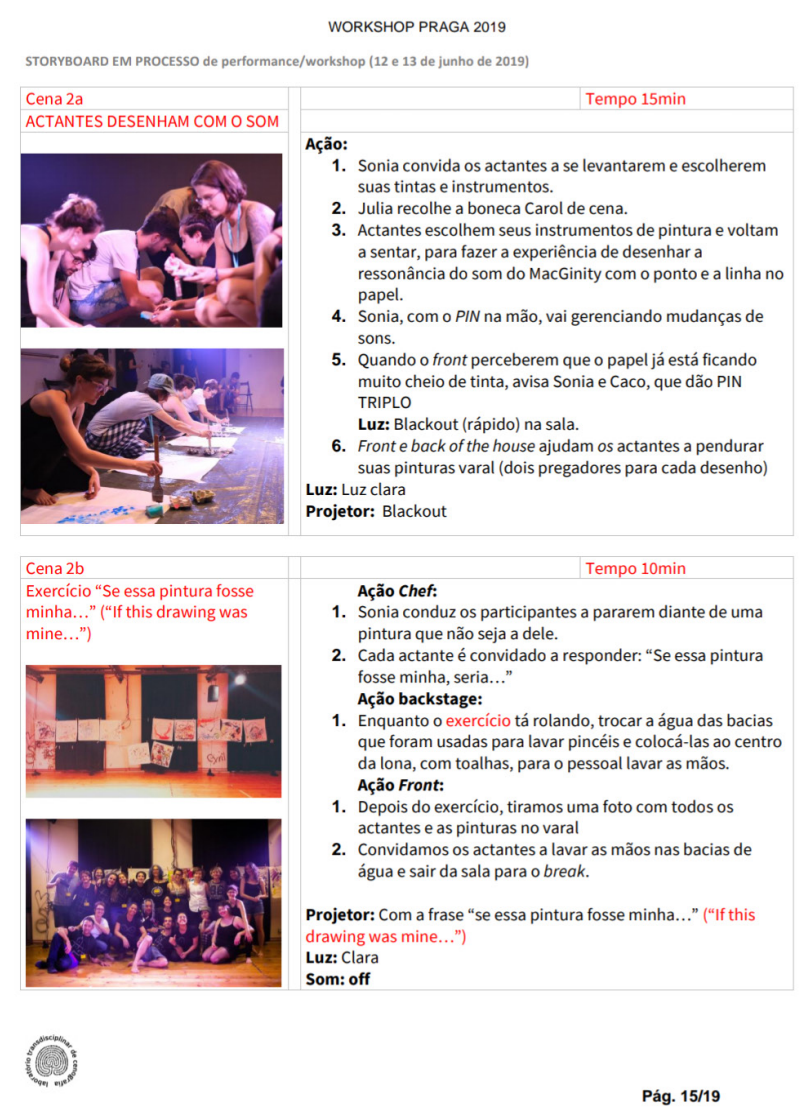

Fonte: Acervo do grupo.

GUIDA: - Sim, você tem razão, Sônia... O ensaio não se limita à experiência ou ato em si, inscrito no espaço e no tempo de cada ação específica, mas talvez, e antes de tudo, o ensaio se relacione com uma compreensão aprofundada e coletiva desse "todo" e as dinâmicas atreladas ao mesmo... Mas, ao mesmo tempo, como é difícil definir esse todo! Ele sempre escapa... Será que detalhar minuciosamente cada ação realizada, de certa forma, não traz o risco de engessar e privar a experiência do workshop de estar aberto ao improviso? JULIA: - Acho que no nosso caso não chegamos perto desse risco! Lembro de outra comparação que a Sônia fez, entre a dinâmica de trabalho do Desenhos Narrativos e a Commedia Dell'arte: onde grupo de atores profissionais, treinados no improviso do diálogo e da ação, trabalhavam a partir de uma trama pré-estabelecida em cima de personagens tipo e roteiros de cenas, os chamados canovaccio, que se comparam com nosso storyboard. Com o storyboard sabíamos para onde ir, sabíamos qual "personagem" iríamos "interpretar", e a partir daí tínhamos o improviso e a liberdade de poder interagir com as pessoas de forma natural, fazer conexões reais e criar soluções inovadoras para imprevistos dados. SÔNIA: - Com o storyboard conseguimos fazer um "teatro jazzístico"! CAIO: - Sim! Para o jazz fluir é necessário não apenas saber tocar seu instrumento, é preciso estar simultaneamente conectado com os outros. Todos conhecem a música inteira, seu timing, suas várias tessituras, jogos harmônicos e melodias do início ao fim, não apenas a sua parte. Achar o momento propício para o improviso, ou ainda estar preparado para fazer a base enquanto os outros improvisam são atitudes fundamentais. Em outras palavras, para esse "teatro jazzístico" funcionar é preciso estar atento ao coletivo ao mesmo tempo que o coletivo está atento a você. BRUNA: - Essa imagem é ótima! Consigo ver o jazz funcionando quando lembro da nossa dinâmica durante o último prato do menu do workshop, o Light painting. Era importante o modo como todos estavam conectados neste momento: o front e o back of the house organizavam os participantes que iriam compor o desenho de luz; a cozinha aumentava e abaixava o som para que fosse possível ouvir o que se falava; dava a marcação de início e término da captura fotográfica com o uso do sino com o "piiiin" inconfundível; provocava um breu para que a luz não interferisse no magia do Light painting e sincronizava captura e projeção com tudo isso. Todos estarem atentos foi o que permitiu improvisarmos como uma banda de jazz quando o programa de captura fotográfica travou, ou quando surgiu uma proposta de Light painting fora do nosso roteiro, a batalha de luzes entre dois times de actantes. CAIO: - É mais do que apenas improvisar. É 
como o Caco falou: é estar atento a tudo para poder encontrar soluções, antes do pepino acontecer. LUA: - E a história do punho quebrado da Sônia? Foi um dos imprevistos de maior preocupação para nós, a solução para isso acabou sendo uma das cenas mais divertidas do workshop! PATRICIA: - Gente, verdade! E vocês lembram que a solução veio antes do problema, né? Antes de Praga, durante o Grito Cultural, fomos fazer o workshop e a Sônia sentiu muita dor nas pernas para sentar-se no chão e desenhar durante o momento do Kandinsky. Então a Ana Carolina se sentou no chão, em frente a Sônia, e disse a ela: "me usa como sua boneca!" (risos)

Figura 14 - Ensaio da "boneca marionete", com Ana Carolina e Sônia Paiva, em Brasília.

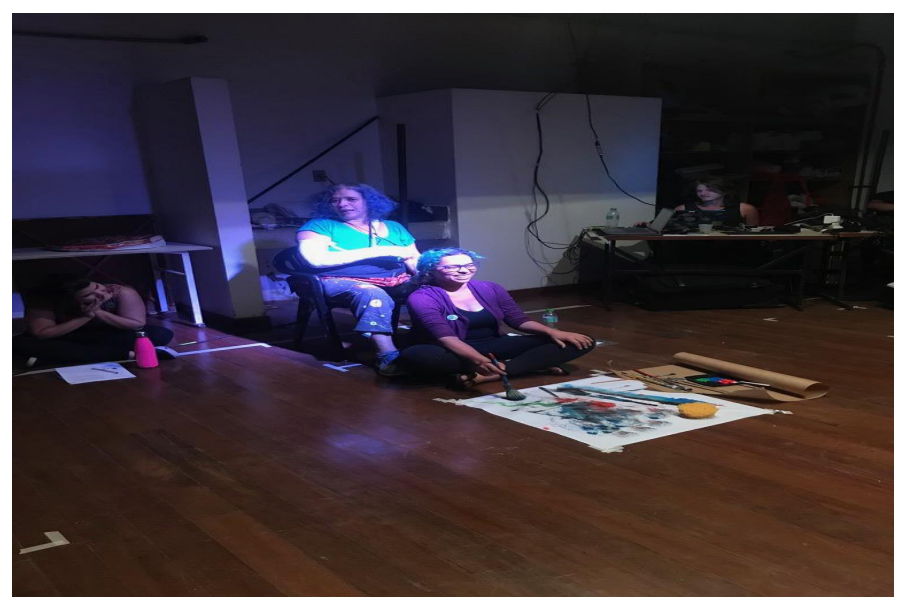

Fonte: Acervo do grupo.

LUA: - Foi ótimo! Carol virou a boneca marionete da narradora! A Sônia guiava os movimentos da boneca pela manipulação das tranças no cabelo dela, e aí surgiam os gestos com os pincéis, realizados pela Sônia e reverberados pela boneca. Foi muito divertido de assistir! $\mathrm{E}$ ainda teve a solução da Júlia de entrar em cena carregando a Carol nas costas, como uma "boneca em tamanho real", o que deixava a construção cênica ainda mais completa. CAIO: - Desde que estou no laboratório percebo que toda a nossa saga de erros gera novas e divertidas criações! Com este trabalho não seria diferente! CACO: - E funciona porque aproveitamos as maquetes, os testes e os ensaios durante nossa produção para errar muito antes de começar a acertar. E os testes são feitos com todos juntos, acompanhando tudo... JULIA: - A comparação com a Commedia Dell'arte abrange também a produção do LTC, já que os artistas da Commedia faziam tudo: transformavam a carroça em palco, costuravam os figurinos, cuidavam da luz e da divulgação, depois ainda passavam o chapéu ao final das apresentações... BRUNA: - Eu amo fazer as coisas com as minhas próprias mãos! Essa dinâmica do LTC, em que fazemos tudo, assim como na Commedia Dell'arte, é, apesar de trabalhosa, muito prazerosa e extremamente propícia ao aprendizado. Para a $P Q$, tivemos que estampar nossas camisetas, costurar aventais, levamos os equipamentos dentro das nossas bagagens no avião... E em Praga, além de fazer a montagem do workshop na DAMU, tivemos que pintar a parede da sala. Olha o quanto pude aprender!

Figura 15 - Montagem do workshop na DAMU, em Praga.

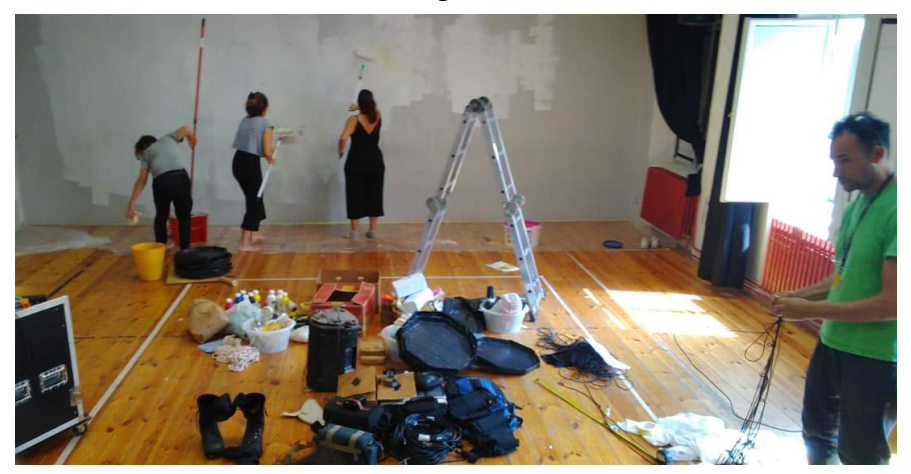

Fonte: Acervo do grupo.

GUIDA: - Dentro do laboratório, podemos ter uma noção muito ampliada da dinâmica, conexão e dependência entre as diversas partes do trabalho, e essa visão global é o que culmina na realização de um projeto completo: esse foi um aprendizado precioso que tive com o LTC. Acredito que a transdisciplinaridade é o que possibilita essa experiência integrada: durante o convívio coletivo existe uma troca constante de conhecimentos entre os integrantes. Assim não só o projeto fica completo, como cada indivíduo do grupo, ao se aproximar de tantas áreas! Eu estudo Arquite- 
tura, mas no workshop experimentei a atuação cênica, narrando um dos desenhos sona aos actantes. Foi incrível como minha percepção do espaço mudou e ganhou uma complementaridade que não esperava! Enxerguei para além do "filtro arquitetônico", tão atrelado à materialidade física, e senti o espaço fortemente sob um ponto de vista particular, junto da potência imaterial e afetiva daquela experiência. BRUNA: - Sinto que precisamos entender sobre fluxo para projetar: como é o dia a dia naquele ambiente, quem são as pessoas e como elas se movimentam no espaço... Pois cada espaço tem suas necessidades próprias, condicionadas à cultura de quem o utiliza, e podemos replicar as soluções como uma receita de bolo para todo projeto. Esse raciocínio, que desenvolvi no contexto do meu curso de Arquitetura, acabou sendo essencial para que eu pudesse entender o trabalho do LTC com o desenho da cena e desempenhar meu papel de back of the house. Projetamos o workshop para a PQ tendo em mente o espaço que teríamos lá. O projeto não teria a mesma qualidade sem: a maquete que construí da sala da DAMU; os estudos da planta da sala no computador; desenhar a planta com fita crepe no chão, para os ensaios em Brasília; e a visita técnica ao espaço, já lá em Praga. Isso porque, só com todos esses recursos, foi possível raciocinar o workshop dentro das necessidades, obstáculos e potencialidades que aquele espaço específico nos oferecia. LUA: - Um bom exemplo foi a gente tentando descobrir, ainda aqui em Brasília, como faríamos para lavar os pincéis sujos de tinta entre uma sessão e outra, encher as bacias que serviriam para os actantes lavarem as mãos... BRUNA: - Sim! Não sabíamos onde o ponto de água estaria, se ficaria longe da sala, se teriam muitos obstáculos no caminho... Com o tempo limitado que teríamos para essa movimentação e o espaço reduzido da sala, tivemos que imaginar qual seria a pior situação possível e já pensarmos em uma solução! Acabou que chegamos em Praga e um ponto de água dentro do camarim que ficava den- tro da sala, o que foi uma super vantagem e não precisamos daquela solução que tínhamos pensado. Mas ao menos sabíamos que não seríamos pegos de surpresa! E para tudo isso foi necessário raciocínio de fluxo! Não só nesse exemplo, mas o tempo todo, como líder do back of the house, eu precisei entender qual era o desenho que as pessoas, tanto da nossa equipe, quanto os actantes, faziam no espaço e planejá-los para que não se chocassem e se encontrassem quando fosse preciso. JúLIA: - Estávamos em estado de criação, estado de alerta. Somos criadores, pesquisadores, técnicos e atores improvisando em conjunto. Criamos cenas e metodologias de ensino. Talvez as dúvidas constantes do grupo de como chamar o projeto - "Experiência-teatro-workshop?", "Espetáculo performativo?", "Workshop espetacularizado?" - brotaram substancialmente por este trabaIho possuir elementos didáticos e espetaculares, sendo que suas proporções estão vinculadas diretamente ao espaço em que o projeto é inserido. CAIO: - É verdade, Júlia... Toda vez que penso no resultado deste workshop, sobretudo o resultado da vivência do público, vejo como há tantas camadas... Por um lado, ele se trata de um percurso na espacialidade. Outra coisa é que esse projeto é um trajeto por libertação da prática criativa... SÔNIA: - Mais do que isso! A forma como as etapas são construídas e relacionadas permite que a pessoa vá libertando a criatividade e a si, gradativamente. Na entrada com a Etnomatemática, sentar-se no chão e ter as mãos em contato direto com a areia é a primeira libertação, mas aprender e seguir desenhos matemáticos e determinados permite que o actante ainda permaneça em uma certa zona de conforto. No prato principal, com a teoria do Kandinsky, ele já é convidado a se expressar emocionalmente e fisicamente por meio da transposição do som para o gesto na pintura, porém, a ação ainda é individual e o trabalho se dá em plano bidimensional. Por fim, é um momento de se deliciar! Vem o Light painting, a sobremesa. Com corpo e mente já aquecidos, o 
actante se empodera completamente de si e de sua reverberação e, nas danças conjuntas, deixa sua marca, mas também afeta a dança dos outros. É um convite a aceitar-se e responsabilizar-se por si e pelo outro. Essa gradação é importante para que o corpo e a mente saiam desse estado estático de maneira não violenta. A palavra-chave é EMPATIA!

Figura 16 - Desenho de luz feito durante o workshop na PQ19.

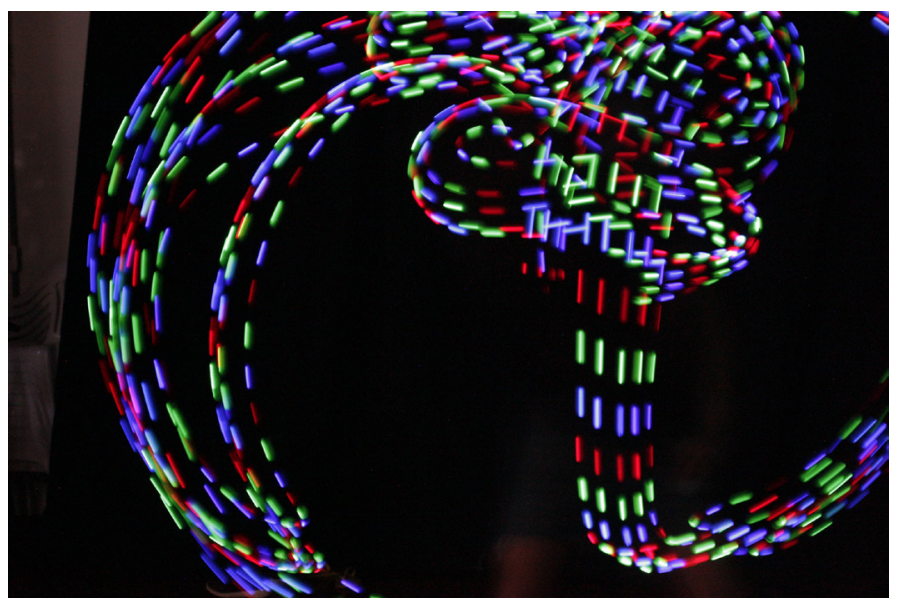

Fonte: Acervo do grupo.

BRUNA: - É isso que torna nosso workshop especial! O público não recebe passivamente um conteúdo regulado e limitado, pelo contrário, ele é convidado a ser protagonista de um caminho de experimentação e imersão em si. Nosso papel é proporcionar o ambiente adequado e as ferramentas para que ele próprio se empodere. O Desenhos Narrativos faz com que o participante ative suas múltiplas inteligências, adormecidas pelo nosso sistema educacional e pela estrutura social em que vivemos. Essa é a causa do êxtase que todos sentem ao final da experiência! Não é à toa que as palavras que mais surgiram nas declarações finais dos actantes foram "liberdade" e seus sinônimos. SARAH: - No bate-papo da última sessão, uma das actantes questionou: como a experiência do Desenhos Narrativos pode contribuir para melhorar o mundo? E a Sônia respondeu que o que aprendemos ali é esse exercício de empatia e autoconhecimento. Partir do in- dividual para entender sua existência no comunitário. BRUNA: - Ah, posso abrir os vídeos dos depoimentos para a Patricia ver? Vou pegar meu notebook. [Bruna abre o notebook e dá início aos vídeos].

Figura 17 - Bate-papo multicultural com os participantes do workshop na PQ19.

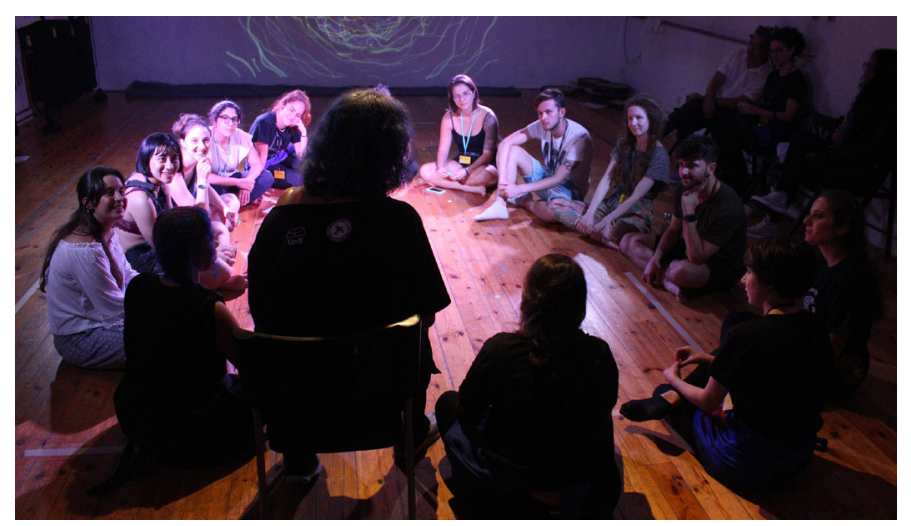

Fonte: Acervo do grupo.

- Eu gostei muito que você (Sônia) não tentou nos ensinar, foi nos guiando pela experiência, assim, pudemos criar em nossas cabeças as interrogações. (Bryan Moses, EUA, participante da $3^{a}$ sessão do workshop na PQ19). - Eu posso ver que as pessoas aqui são diferentes das que entraram nessa sala há algumas horas atrás. Essa foi uma das experiências mais maravilhosas que eu já tive em 10 anos morando aqui em Praga. Então, muito obrigada. [...] Eu venho de um país muito caloroso e em que ficamos emocionados com tudo, mas eu moro aqui (Praga), então, vivo nesse conflito. Pensando no tipo de mudança que podemos acarretar no mundo, entendo que, se as pessoas estão mais felizes e se sentem tocadas, elas tomarão melhores decisões. Não acredito que precisamos tocar milhões de pessoas, mas se eu sou melhor, já estou fazendo algo de bom para o mundo. [...] Neste momento, no Brasil, por 
conta do nosso presidente, não temos um ministro da cultura. $\mathrm{E}$ termos aqui um grupo nos proporcionando isso (o workshop Desenhos Narrativos), pra mim, é a maior demonstração de resistência. (Graziela, Brasil, participante da $4^{\mathrm{a}}$ sessão do workshop na PQ19).

SÔNIA: - Eu sempre pensei que, se pudéssemos ver no rosto dos participantes aquele olhar de "Eureka!", de "Descobri que sou capaz!", todo nosso esforço valeria a pena. E assim poderíamos ter no Desenhos Narrativos um trabalho autoral que nos representa! E assim foi!
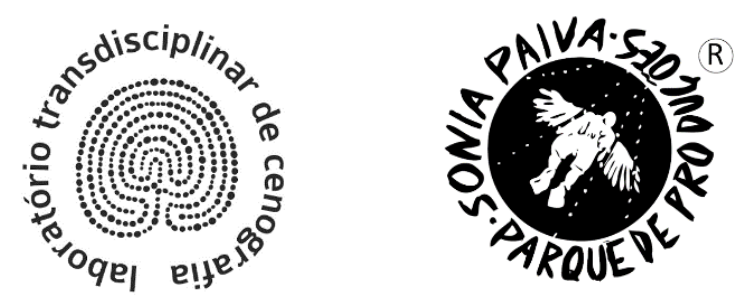

\section{Referências}

D'AMBRÓSIO, Ubiratan. Elo entre as Tradições e a Modernidade. São Paulo: Summus, 2001.

Paulo: Palas Athena, 2012.

Transdisciplinaridade. São

PAIVA, M. C. Sônia (Org.). Brasil: LABirintos Compartilhados. Brasília: Laboratório Transdisciplinar de Cenografia, 2015.

O Laboratório Transdisciplinar de Cenografia (LTC): lócus do espaço e desenho da cena no Brasil. 2016. 224 f., Tese (Doutorado em Artes), Universidade de Brasília, Brasília, 2016.

O Laboratório Transdisciplinar de Cenografia (LTC) e a Quadrienal de Praga. Disponível em: <https://www.academia.edu/33683505/O_ Laborat\%C3\%B3rio_Transdisciplinar_de_Cenografia_LTC_e_a_Quadrienal_de_Praga.docx $>$.
PAIVA, S.; VERAS, L. Olhares sobre a educação do desenho de cena. Participação, n. 25, 25 ago. 2014. Disponível em: <http://periodicos.unb.br/index.php/ participacao/article/view/16945/15236>.

Recebido: 31/08/2019

Aprovado: 17/02/2020 